Revista

Ibero-Americana

de Estratégıa

\title{
ESTRATÉGIA DE INTERNACIONALIZAÇÃO DE FIRMAS BRASILEIRAS E
} DESEMPENHO FINANCEIRO

INTERNATIONALIZATION STRATEGY AND FINANCIAL PERFORMANCE IN BRAZILIAN FIRMS

ESTRATEGIA DE INTERNACIONALIZACIÓN DE EMPRESAS BRASILEÑAS Y SU DESEMPEÑO FINANCIERO

\section{Pedro Paulo Mendes Silva}

Graduado em Administração pelo Centro Universitário Álvares Penteado - FECAP

E-mail: pedropma@yahoo.com.br (Brasil)

\section{João Maurício Gama Boaventura}

Doutor em Administração pela Universidade de São Paulo - USP

Professor da Faculdade de Economia, Administração e Contabilidade da Universidade de São Paulo

- FEA/USP

E-mail: jboaventura@usp.br (Brasil) 


\section{ESTRATÉGIA DE INTERNACIONALIZAÇÃO DE FIRMAS BRASILEIRAS E DESEMPENHO FINANCEIRO}

\section{RESUMO}

A internacionalização da firma e o aparecimento de empresas multinacionais não é um acontecimento recente, datam do início da Idade Moderna as primeiras iniciativas em realizar negócios além mar e, dessa forma, incrementar os lucros. Para as empresas brasileiras, em particular, este fenômeno ganhou destaque a partir da década de 1990, com a abertura comercial do país. O objetivo deste estudo é analisar a estratégia de internacionalização de empresas brasileiras, mais particularmente os casos das empresas de capital aberto com investimento direto no exterior superior à US\$ 10 milhões, e a relação com o desempenho financeiro dessas empresas. Por meio de um estudo quantitativo, empregando o índice de internacionalização e a variação do desempenho financeiro, desenvolveu-se uma análise da relação entre o processo de internacionalização e os indicadores de desempenho financeiro nas nove empresas que compõe a amostra não-probabilística por conveniência. Os resultados encontrados permitiram concluir que há uma correlação positiva fraca, com indicadores financeiros de crescimento, enquanto as métricas de rentabilidade apontam para uma relação negativa em algumas das variáveis independentes utilizadas.

Palavras-chave: Desempenho Financeiro; Internacionalização de Empresas; Rentabilidade Financeira.

\section{INTERNATIONALIZATION STRATEGY AND FINANCIAL PERFORMANCE IN BRAZILIAN FIRMS}

\section{ABSTRACT}

The internationalization of the firm and the appearance of multinational companies are not recent events. The first initiatives to realize businesses overseas and increase profits in this way date from the beginning from the Modern Age. For Brazilian companies in particular, this phenomenon has been gaining attention since the 1990s, with the commercial opening of the country. The objective of this study was to analyze the strategy of internationalization in Brazilian companies, in particular the case of publically traded companies with foreign direct investments greater than $\$ 10$ million, and the relation with the financial performance of these companies. Through a quantitative study using the rate of variation of internationalization and financial performance, researchers developed an analysis of the relation between the process of internationalization and financial performance indicators in nine companies that make up the non-probabilistic sample of convenience. The results concluded that there is a weak positive correlation with financial indicators of growth; profitability metrics show a negative relationship in some of the independent variables.

Keywords: Internationalization of Firms; Financial Performance.

Revista Ibero-Americana de Estratégia - RIAE, São Paulo, v. 10, n. 3, p. 04-21, set./dez. 2011. 


\section{ESTRATEGIA DE INTERNACIONALIZACIÓN DE EMPRESAS BRASILEÑAS Y SU DESEMPEÑO FINANCIERO}

\section{RESUMEN}

La internacionalización de la empresa y la aparición de empresas multinacionales no es un acontecimiento reciente, datan del inicio de la Edad Moderna las primeras iniciativas en realizar negocios más allá del mar y de esa manera aumentar las ganancias. Para las empresas brasileñas, en particular, este fenómeno viene ganando destaque a partir de la década de 1990, con la apertura comercial del país. El objetivo de este estudio es analizar la estrategia de internacionalización de empresas brasileñas, en particular los casos de las empresas de capital abierto con Inversión Directa en el Exterior superior a U\$ 10 millones, y la relación con el desempeño financiero de esas empresas. Por medio de un estudio cuantitativo empleando el índice de internacionalización y la variación del desempeño financiero se desarrolló un análisis de la relación entre el proceso de internacionalización y los indicadores de desempeño financiero en las nueve empresas que componen la muestra no probabilística por conveniencia. Los resultados encontrados permitieron concluir que hay una correlación positiva débil con los indicadores financieros de crecimiento, mientras las métricas de rentabilidad indican una relación negativa en algunas de las variables independientes utilizadas.

Palabras-clave: Internacionalización de Empresas; Desempeño Financiero; Rentabilidad Financiera. 


\section{INTRODUÇÃO}

O comércio internacional é objeto de estudo e ação de governos e iniciativas particulares desde os primórdios da Idade Moderna, época em que os povos considerados mais desenvolvidos e ricos detinham a poder sobre as navegações e o comércio inter nações. Pode-se destacar, nesse processo, o papel fundamental exercido na economia mundial pela Companhia das Índias Orientais, que foi considerada como embrião da empresa moderna (Micklethwait e Wooldridge, 2003). A corporação, criada em 1599 em Londres com o aval da Rainha e Família Real (sócios majoritários), financiou a produção de matérias-primas, tais como chá, seda, porcelana, especiarias em países asiáticos e africanos com a intenção de exportá-las para o mercado europeu atingindo lucros generosos.

No entanto, o estudo de empresas internacionais apenas tornou-se tema de pesquisas acadêmicas com o significante fluxo de investimentos entre os países no pós-Segunda Guerra Mundial. Entre os pioneiros, Vernon (1966) foi o acadêmico de destaque ao desenvolver o modelo de ciclo do produto de Investimento Externo Direto (IED), enfatizando a importância do mercado americano e da Pesquisa e Desenvolvimento (P\&D) no crescimento das empresas locais.

A criação do periódico Journal of International Business Studies (JIBS) pela Academy of International Business demonstra a relevância que este tema passou a ter no meio acadêmico na década de 1960. Entretanto, Inkpen e Bemish (1994) relatam que as pesquisas ainda eram concentradas em pesquisadores norte-americanos, responsáveis por, aproximadamente, 93\% das pesquisas no período entre os anos 1970 e 1974. Os estudos nessa área passaram a ter importância mundial crescente nas décadas seguintes e, principalmente, no Brasil a partir dos anos de 1990, com a abertura comercial do país.

Batista Jr. e Nogueira (1998) argumentam que o fenômeno da atuação internacional, embora não seja recente em países desenvolvidos, está ganhando grande destaque no Brasil. É crescente a quantidade de empresas nacionais que integram a pesquisa do Boston Consulting Group, acerca das 100 empresas de países emergentes com maior potencial de internacionalização comercial e de Investimentos Diretos no Exterior (IDE) (Boston Consulting Group, 2003; 2009)

No entanto, as publicações a respeito do assunto internacionalização de empresas no ambiente acadêmico nacional são, em sua maioria, focadas a) nas estratégias utilizadas para inserção em novos mercados e seus desdobramentos (Mariotto, 2007, Vasconcellos, 2008), b) processos de entrada e c) produtos e marcas. Considerando a argumentação de Berk e Demarzo (2007) acerca do propósito intrínseco de perpetuar-se das empresas surge o seguinte 
questionamento: Há relação entre o grau de internacionalização da empresa e seu desempenho financeiro?

Pesquisadores de diferentes partes do mundo têm pesquisado sobre a existência de uma relação como questionada anteriormente e há grande divergência nos resultados até então apresentados. Ruigrok e Wagner (2003), Lu e Beamish (2004), Barcellos (2010) realizaram recentemente estudo acerca da relação entre essas variáveis e encontraram resultados confrontantes como uma relação em forma de $\mathrm{U}$ no primeiro e $\mathrm{U}$ invertido na pesquisa do segundo. Barcellos (2010) ainda acrescenta que é restrito o número de estudos realizados com o intuito de analisar essa relação nas empresas brasileiras.

Identificar e analisar a relação entre tais fatores é uma forma de entender os benefícios e custos gerados no processo de busca de novos mercados além fronteiras brasileiras. De forma empírica, as relações que se pretende analisar por meio deste estudo estão relacionadas às perspectivas iniciais da empresa em se esforçar para tornar-se uma corporação multinacional e o impacto em seu desempenho.

\section{FUNDAMENTAÇÃO TEÓRICA}

\subsection{INTERNACIONALIZAÇÃO}

Este estudo não pretende esgotar o assunto, mas entender como a internacionalização de empresas é vista modernamente pela academia. Entre as principais teorias e abordagens de relevância no estudo da internacionalização de empresas, destaca-se a Escola de Uppsala ou Nórdica, da qual Johanson e Wiedersheim-Paul (1975) foram precursores. Já a as Teoria da Internalização (Buckley e Casson, 1976) e a dos Custos de Transação (Williamson e Chandler, 1975) destacam-se pela abordagem estratégica ou paradigma eclético (Dunning, 1980).

A abordagem estratégica, que trata das questões de planejamento e estrutura, ou seja, da arquitetura organizacional, focaliza a multinacional como um todo e o conhecimento gerado no que diz respeito a organização. Porter (1990) propôs essa abordagem, onde a prosperidade nacional é criada e não herdada e em que sua competitividade dependerá da capacidade de inovação e modernização de seus setores industriais. Essa capacidade de inovação se tornará uma vantagem, a partir do momento que as pressões e os desafios locais empurrarem as firmas na busca de melhorias. Um ambiente competitivo, com fortes concorrentes, fornecedores agressivos e clientes exigentes, é extremamente favorável para o desenvolvimento de vantagens competitivas.

Revista Ibero-Americana de Estratégia - RIAE, São Paulo, v. 10, n. 3, p. 04-21, set./dez. 2011. 
São diversas as estratégias adotadas pelas firmas que ocupam posição de destaque no mercado internacionalizado, mas em todas elas o modo de operação é idêntico. As empresas ganham vantagens competitivas pela inovação, tanto em termos de tecnologias quanto em termos de novos modos de fazer as coisas.

\begin{abstract}
Algumas inovações criam vantagem competitiva por perceberem uma oportunidade de mercado inteiramente nova ou atenderem a um segmento de mercado que os demais ignoraram. [...] Nos mercados internacionais as inovações que trazem vantagens competitivas antecipam necessidades tanto domésticas como internacionais. (Porter, 1990).
\end{abstract}

Desenvolvido por Dunning (1980), o paradigma eclético reuniu contribuições de diversas teorias da abordagem econômica. $\mathrm{O}$ autor defende que para uma firma iniciar sua produção internacional, deve possuir algumas vantagens diferenciais sobre seus competidores. Dunning (1980) procura explicar o movimento de internacionalização a partir de três grupos de vantagens que influenciam na decisão de produzir no exterior: propriedade, localização e internalização. A respeito desses grupos de vantagens, Tanure e Duarte (2006) explicam que:

- Vantagens de propriedade: Específicas da firma. Podem ser vantagens tangíveis, como a tecnologia, que pode ser comercializada; ou intangíveis, como a capacidade de gerar tecnologia, as competências organizacionais, a capacidade de empreendedorismo da firma, a experiência em produzir no exterior, entre outros (Tanure e Duarte, 2006);

- Vantagens de localização: Relacionadas ao mercado que recebe o investimento, com a vantagem de facilitar a obtenção de benefícios econômicos existentes em locais diferentes, tais como menores custos de produção; mão de obra barata; capital; matérias-primas e outros insumos; proximidade dos clientes, reduzindo o custo transporte (Tanure e Duarte, 2006); e

- Vantagens da internalização: Caracteriza-se pela maior conveniência para a firma transferir ativos, utilizando sua própria estrutura e hierarquia, do que utilizar-se de agentes externos (Tanure e Duarte, 2006).

De uma forma geral, o paradigma eclético busca explicar os motivos pelos quais a firma abre instalações de produção no exterior e não há a intenção de explicar como se dá a busca de mercados no exterior. (Dunning, 1980). No entanto, há outras abordagens para a explicação dos motivadores.

Revista Ibero-Americana de Estratégia - RIAE, São Paulo, v. 10, n. 3, p. 04-21, set./dez. 2011. 
Segundo Rocha (2003), há sete fatores principais que podem ser considerados como estímulos em um processo de internacionalização são: a) Busca de novos mercados que permitem a expansão das vendas além de um mercado doméstico supostamente saturado; b) Procura de recursos no mercado estrangeiro: as firmas podem instalar-se em outros países para diminuir os custos dos bens e serviços que produzem; c) Busca de conhecimento especializado, presença em mercados internacionais gera a oportunidade de aprender a partir das diferenças; d) Redução do risco, que pode ser proporcionada pela atuação em mais de um mercado; e) Retorno sobre o investimento, em um mundo globalizado e muito mais competitivo, muitas vezes é necessário para a venda em grande escala.; f) Manobra competitiva: no âmbito global refere-se a uma empresa, que compete com uma rival em vários países, ver-se obrigada a acompanhar a entrada da rival em um novo país, para evitar perda de participação no mercado internacional; e g) Prestígio local, prevê que o sucesso internacional de uma empresa a torna mais competitiva no local de origem (Rocha, 2003).

Para Bartlett, Ghoshal e Birkinshaw (2004), as empresas podem ser empurradas ou atraídas pelos novos mercados. Segundo os autores, a busca por matéria-prima em distantes pontos do globo terrestre é uma realidade desde o início do século XX. Datam dessa época empresas, principalmente sediadas nos Estados Unidos, produtoras de alumínio, pneus e óleo que partiram mundo afora em busca de furar novos poços de extração de petróleo, jazidas de bauxita, entre outros produtos minerais.

Ainda conforme os autores, diversas empresas europeias detentoras de vantagem competitiva sobre seus concorrentes locais, em geral proporcionadas pelo uso de tecnologia avançada ou preferência do mercado, viam seu crescimento estagnado. Tal fenômeno se devia ao pequeno mercado em que estavam sediadas ser insuficiente para absorver qualquer aumento de produção dessas firmas. Desta forma, a expansão além fronteiras é vista como único meio de trazer crescimento positivo para os balanços empresariais. São exemplos dessa atração exercida pelos novos mercados: a indústria de alimentos, automóveis e medicamentos.

Finalmente, o terceiro principal gatilho para a internacionalização trata-se da procura por fatores de produção de baixo custo. Desde sempre o custo de se produzir é preocupação latente do administrador. Particularmente, a redução das barreiras tarifárias entre os países Europeus e os Estados Unidos na década de 1960 proporcionou travessias de oceanos em busca do menor custo. Tal circunstância resultou a partir da década de 1980 em empresas multinacionais que possuem suas operações mundiais e não mais domésticas como até então.

Neste estudo, adotou-se o conceito de internacionalização proposto por Bartlett et al. (2004), em que as empresas encontram a internacionalização como forma de prover crescimento para seus

Revista Ibero-Americana de Estratégia - RIAE, São Paulo, v. 10, n. 3, p. 04-21, set./dez. 2011. 
resultados ou, utilizando-se de fatores operacionais externos, para obter vantagem competitiva em relação a seus concorrentes.

Nesse sentido, Barcellos (2010), argumenta que, da mesma forma que outros projetos de investimento, as empresas que se internacionalizam esperam obter resultados e retornos, a despeito dos riscos e custos assumidos ao decidir estrategicamente por essa opção. Dessa forma, a autora sugere que sejam realizadas pesquisas para melhor compreensão da relação entre a internacionalização e o desempenho financeiro dessas empresas. Contractor et al. (2003) argumenta que a aferição de resultados positivos e uma relação positiva entre a estratégia de internacionalização e desempenho financeiro são fundamentais para o estudos dos negócios internacionais, porém ainda necessitam de mais estudos e pesquisas.

\subsection{DESEMPENHO FINANCEIRO}

Boshoff e Mels (1995) sugerem que o objetivo de medir o desempenho está associado à maximização dos recursos investidos, propósito de qualquer organização, seja ela fundação, governo, privada com ou sem fins lucrativos. No entanto, não há um consenso sobre uma metodologia de mensuração do desempenho das empresas. Venkatraman e Ramanujam (1987) entendem que o desempenho pode ser classificado em três níveis distintos. A figura 1 apresenta os domínios de medição do desempenho.

Figura 1- O domínio do desempenho da empresa.

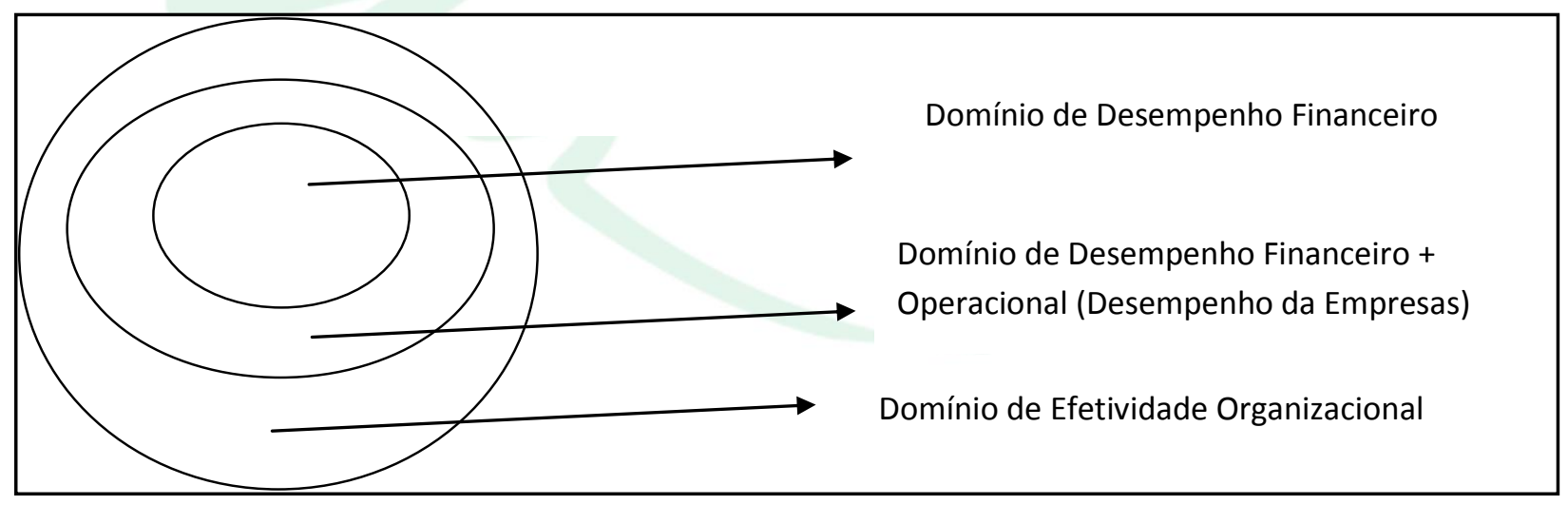

Fonte: Venkatraman e Ramanujam (1987).

Conforme esse esquema, o domínio interno, objeto de pesquisa deste estudo, deve ser analisado a luz de indicadores estritamente financeiros. No entanto, Venkatraman e Ramanujam

Revista Ibero-Americana de Estratégia - RIAE, São Paulo, v. 10, n. 3, p. 04-21, set./dez. 2011. 
(1987) classificam a análise da performance financeira em duas dimensões distintas: crescimento e rentabilidade. Acrescentam ainda que ambas as dimensões podem ser mensuradas por diversos índices comumente utilizados por acadêmicos e executivos.

Berk e DeMarzo (2007) sugerem que o indicador mais importante ao se estudar a rentabilidade de uma empresa é o lucro líquido. Também tratado como demonstrativo dos resultados, esse indicador lista o somatório de receitas e despesas (ligadas ou não a operação) da empresa ao longo de determinado período de tempo.

Entre outros indicadores de desempenho e valor de uma empresa, os autores, destacam a margem operacional e margem do lucro líquido. A primeira, trata da razão entre o resultado operacional (lucro antes do pagamento de impostos) e suas receitas totais. Este indicador revela quanto uma empresa lucra antes dos juros e impostos para cada unidade monetária em vendas. Comparando as margens operacionais de diferentes empresas de uma mesma indústria, pode-se medir a eficiência relativa das operações das empresas ou sugerir tendências estratégicas das empresas.

A razão entre o lucro líquido e a receita denomina-se margem de lucro líquido, que demonstra a parcela de cada unidade monetária da receita que está disponível aos sócios após a empresa pagar todos os seus encargos. Tal indicador dá mostras sobre a eficiência global da organização (Berk e Demarzo, 2007).

O crescimento de uma empresa pode ser medido por meio de indicadores que fornecem a evolução de certos fatores em um período de tempo determinado. São exemplos disso, o crescimento do número de funcionários, variação da receita líquida, número de plantas, entre outros.

Para Ross, Westerfield e Jaffe (2009), o retorno sobre o patrimônio líquido representa "a rentabilidade de todo o capital próprio da empresa, correspondendo à taxa de retorno de todos os projetos acumulados". É definido pela razão entre o lucro líquido e o patrimônio líquido (também identificado como capital próprio).

Para fins compreensão do objetivo deste trabalho, este estudo irá considerar o constructo financeiro multidimensional, proposto por Venkatraman e Ramanujam (1987), empregando as ferramentas ideais para mensuração de crescimento e rentabilidade dos resultados organizacionais (Berk e Demarzo, 2007; Ross, Westerfield et al., 2009).

No entanto, quando se trata de analisar o desempenho de empresas em diferentes países Hult et al.(2008) identificaram dificuldades peculiares. O autor argumenta que a construção do constructo, que permite analisar essas relações, é ainda mais complexa, devido aos padrões 
Estratégia de Internacionalização de Firmas Brasileiras e Desempenho Financeiro

contábeis divergentes, e as operações com escopos geográficos e vantagens diferentes. Nesse sentido, Hult et al.(2008) realizaram uma meta-análise com base em 96 investigações empíricas em busca de identificar as principais medidas de desempenho no estudo da relação entre o grau de internacionalização e a performance financeira. Como resultado, os autores obtiveram as principais ferramentas e a porcentagem de estudos da amostra se utilizaram dessa ferramenta separadas pelo nível de análise.

Tabela 1- Medidas de desempenho utilizadas com maior frequência.

\begin{tabular}{|c|c|c|c|}
\hline $\begin{array}{l}\text { NÍVEL DE } \\
\text { ANÁLISE }\end{array}$ & $\begin{array}{l}\text { DESEMPENHO } \\
\text { FINANCEIRO }\end{array}$ & $\begin{array}{l}\text { DESEMPENHO } \\
\text { OPERACIONAL }\end{array}$ & $\begin{array}{l}\text { DESEMPENHO DE } \\
\text { EFICÁCIA GERAL }\end{array}$ \\
\hline \multirow{2}{*}{ Empresa } & $\begin{array}{l}\text { Baseado em vendas: } \\
44 \%\end{array}$ & \multirow{2}{*}{$\begin{array}{l}\text { Participação de } \\
\text { mercado: } 47 \%\end{array}$} & \multirow{2}{*}{ Reputação: $30 \%$} \\
\hline & $\begin{array}{l}\text { Retorno sobre o ativo: } \\
40 \%\end{array}$ & & \\
\hline \multirow{2}{*}{$\begin{array}{c}\text { Unidade } \\
\text { estratégica de } \\
\text { negócios }\end{array}$} & $\begin{array}{l}\text { Baseado em vendas: } \\
68 \%\end{array}$ & \multirow{2}{*}{$\begin{array}{l}\text { Participação de } \\
\text { mercado: } 46 \%\end{array}$} & $\begin{array}{l}\text { Desempenho em relação aos } \\
\text { concorrentes: } 50 \%\end{array}$ \\
\hline & $\begin{array}{c}\text { Retorno sobre o } \\
\text { investimento: } 47 \%\end{array}$ & & $\begin{array}{l}\text { Desempenho geral percebido: } \\
33 \% \\
\end{array}$ \\
\hline \multirow{3}{*}{$\begin{array}{l}\text { Unidade inter- } \\
\text { organizacional }\end{array}$} & $\begin{array}{l}\text { Baseado em vendas: } \\
62 \% \\
\end{array}$ & Produtividade: $44 \%$ & \multirow{3}{*}{$\begin{array}{l}\text { Desempenho geral percebido: } \\
71 \%\end{array}$} \\
\hline & \multirow{2}{*}{ Lucratividade: $31 \%$} & $\begin{array}{c}\text { Participação de } \\
\text { mercado: } 33 \%\end{array}$ & \\
\hline & & $\begin{array}{c}\text { Qualidade dos } \\
\text { produtos/serviços: } 33 \%\end{array}$ & \\
\hline \multirow{3}{*}{ TOTAL } & $\begin{array}{l}\text { Baseado em vendas: } \\
52 \% \\
\end{array}$ & $\begin{array}{c}\text { Participação de } \\
\text { mercado: } 44 \%\end{array}$ & $\begin{array}{l}\text { Desempenho geral percebido: } \\
47 \% \\
\end{array}$ \\
\hline & $\begin{array}{l}\text { Retorno sobre o ativo: } \\
29 \% \\
\end{array}$ & \multirow{2}{*}{ Produtividade: $20 \%$} & \multirow{2}{*}{$\begin{array}{c}\text { Desempenho em relação aos } \\
\text { concorrentes: } 20 \%\end{array}$} \\
\hline & Lucratividade: $26 \%$ & & \\
\hline
\end{tabular}

Fonte: Hult et al. (2008).

\section{METODOLOGIA}

Segundo Marconi e Lakatos (2003), o método comparativo se mostra mais adequado para estudos com a "finalidade de verificar similitudes e explicar divergências". Utilizando-se dessa metodologia, é possível compreender organizações em iguais ou diferentes estágios. No caso deste estudo, é possível estabelecer a relação entre o índice de internacionalização e o desempenho financeiro. As autoras ainda acrescentam que os fatores presentes e ausentes podem, até certo ponto, sugerir causas e explicações. Utilizando-se do estudo comparativo combinado com o 
descritivo "pode-se averiguar analogia entre ou analisar os elementos de uma estrutura" (Marconi e Lakatos, 2003).

Esta pesquisa tem como objetivo primário determinar a existência ou ausência de alguma relação entre diferentes variáveis quantitativas do grau de internacionalização e o desempenho financeiro das respectivas companhias. Para tal, foi utilizado um horizonte temporal dos últimos cinco anos em uma amostra não-probabilística por conveniência. A amostra consiste em nove empresas dos seguintes setores: alimentos; metalurgia e siderurgia; construção e engenharia; eletroeletrônico; transportes e logísticas; perfumaria e cosméticos; tecnologia da informação; e têxtil, couro e vestuário. Para este estudo, apenas foram consideradas empresas de capital aberto com relatórios de administração publicados pela Companhia de Valores Mobiliários (CVM) e auditados por companhias independentes de auditoria.

Para a operacionalização da variável internacionalização, optou-se pela metodologia desenvolvida pela Conferência das Nações Unidas sobre o Comércio e Desenvolvimento (Unctad, 2010), aplicada no mercado brasileiro pelo Jornal Valor Econômico (2009) em parceria com a Sociedade Brasileira de Estudos de Empresas Transnacionais e da Globalização Econômica (SOBEET). Para a realização da pesquisa realizada pela Unctad (2010), foram consideradas 173 empresas brasileiras com atuação internacional e investimento direto no exterior superior a US\$ 10 milhões. Tal indicador considera a proporção (internos e externos) entre os três seguintes fatores:

- Empregos, proporção de funcionários contratados no exterior pela quantidade total;

- Ativos, proporção de ativos localizados no exterior pela quantidade total; e

- Receitas, relação entre as receitas advindas de outros mercados pelo faturamento global da empresa.

Como síntese dos três indicadores utilizados na metodologia, utiliza-se o "Índice de Internacionalização", média simples da proporção externa/total dos três fatores, como representação do esforço e presença internacional das empresas.

Quanto à operacionalização da variável desempenho financeiro, foram utilizados indicadores extraídos dos balanços contábeis publicados oficialmente pelas empresas com a aprovação da (CVM), autarquia federal responsável pela harmonia e simetria informacional do mercado de valores mobiliários brasileiro. Entretanto, Venkatraman e Ramanujam (1987) argumentam que a variável desempenho financeiro configura-se como um constructo multidimensional, e, desta forma, deve ser analisada sobre dois diferentes prismas: crescimento e rentabilidade.

Desse modo, este estudo utilizou-se dos seguintes indicadores de crescimento:

Revista Ibero-Americana de Estratégia - RIAE, São Paulo, v. 10, n. 3, p. 04-21, set./dez. 2011. 
- Receita líquida;

- Crescimento da receita líquida;

Para análise da rentabilidade apresentada pelas empresas, foram utilizadas as seguintes ferramentas contábeis:

- Lucro líquido;

- Margem líquida;

- Margem operacional;

- Retorno sobre o patrimônio líquido.

Para a análise estatística dos dados coletados nas nove empresas estudadas e estabelecimento da relação entre as variáveis, foi utilizado o coeficiente de correlação como "medida de intensidade da associação linear entre duas variáveis"(Anderson, Sweeney et al., 2011). Os autores indicam que, por meio desse método, é possível identificar a relação de influência (positiva, neutra ou negativa) entre as variáveis estudadas. Assim como também é possível compreender a força da relação existente. Conforme a Tabela 2, Santos (2007) propõe uma classificação como referência para interpretação dos parâmetros obtidos.

Tabela 2- Classificação da correlação.

\begin{tabular}{|l|l|}
\hline $\begin{array}{c}\text { Coeficiente } \\
\text { de correlação }\end{array}$ & Correlação \\
\hline$r=1$ & Perfeita positiva \\
\hline $0,8 \leq r<1$ & Forte positiva \\
\hline $0,5 \leq r<0,8$ & Moderada positiva \\
\hline $0,1 \leq r<0,5$ & Fraca positiva \\
\hline $0<r<0,1$ & Ínfima positiva \\
\hline 0 & Nula \\
\hline$-0,1<r<0$ & Ínfima negativa \\
\hline$-0,5<r \leq-0,1$ & Fraca negativa \\
\hline$-0,8<r \leq-0,5$ & Moderada negativa \\
\hline$-1<r \leq-0,8$ & Forte negativa \\
\hline$r=-1$ & Perfeita negativa \\
\hline
\end{tabular}

Fonte: Extraído de Santos (2007).

Revista Ibero-Americana de Estratégia - RIAE, São Paulo, v. 10, n. 3, p. 04-21, set./dez. 2011. 


\section{ANÁLISE DOS RESULTADOS}

A análise dos dados, por meio do coeficiente de correlação de Pearson, permite compreender a associação entre as variáveis dependentes e outras independentes. Não se buscou, nesta pesquisa, compreender a causa ou razão específica que explica a relação entre essas variáveis. As correlações entre essas variáveis estão relacionadas na Tabela 3. Nota-se significativa relação positiva com a variável receita líquida e enquanto margem operacional e líquida apresentam relação negativa.

Tabela 3- Correlação de Pearson para variáveis independentes.

\begin{tabular}{|c|c|c|c|c|}
\hline & $\begin{array}{c}\text { GRAU DE } \\
\text { INTERNACIONALIZAÇÃO }\end{array}$ & EMPREGOS & ATIVOS & VENDAS \\
\hline Receita líquida & 0,758127779 & 0,685879042 & 0,66550247 & 0,808017516 \\
\hline $\begin{array}{c}\text { Crescimento receita } \\
\text { líquida }\end{array}$ & 0,345462358 & 0,353150188 & 0,255566075 & 0,381156041 \\
\hline Lucro operacional & 0,226541694 & 0,122951005 & 0,28643768 & 0,231480008 \\
\hline Margem operacional & $-0,374189496$ & $-0,329689959$ & $-0,358369618$ & $-0,381328883$ \\
\hline Lucro líquido & 0,028496443 & $-0,061692589$ & 0,111882401 & 0,024152038 \\
\hline Margem líquida & $-0,42200109$ & $-0,440375361$ & $-0,365416276$ & $-0,410017224$ \\
\hline Patrimônio líquido & 0,555192889 & 0,524839504 & 0,454806333 & 0,598921449 \\
\hline $\begin{array}{c}\text { Retorno sobre } \\
\text { Patrimônio líquido }\end{array}$ & 0,248580242 & 0,218519958 & 0,284077006 & 0,216061319 \\
\hline
\end{tabular}

Fonte: Elaborado pelos autores.

Observa-se que a variável receita líquida apresenta correlação moderada positiva com o grau de internacionalização, empregos e ativos. Enquanto a mesma variável possui correlação forte positiva com a dependente vendas. Dessa forma, expõe que, entre as empresas pesquisadas, há significativa relação entre a estratégia de internacionalização e o faturamento líquido da companhia. Isto é, quanto mais as empresas buscam se internacionalizar no cenário estudado, maiores são as receitas totais e mais forte ainda é a relação entre as receitas captadas fora do país e seu faturamento.

Crescimento da receita líquida, lucro operacional e retorno sobre o patrimônio líquido apresentam relação fraca positiva em todas variáveis dependentes analisadas neste estudo. Entendese que é pouco possível relacionar entre a estratégia de busca por novos mercados com o desempenho financeiro, seja de crescimento ou de rentabilidade.

A variável independente lucro líquido apresenta relação ínfima negativa com a proporção de empregos fora do país, ínfima positiva com a proporção de vendas e ao grau de internacionalização

Revista Ibero-Americana de Estratégia - RIAE, São Paulo, v. 10, n. 3, p. 04-21, set./dez. 2011. 
da firma. Enquanto apresenta, ao mesmo tempo, uma relação fraca positiva com a variável ativos. Dessa forma, não é possível estabelecer qualquer relação ou compreender os resultados obtidos pela internacionalização no desempenho financeiro.

No entanto, nota-se que as variáveis a) margem operacional e b) margem líquida apresentam relação fraca negativa com todas as variáveis dependentes. Compreende-se, a partir desses dados, que uma estratégia de internacionalização proporciona recrudescimento nos indicadores financeiros, principalmente nestes ligados à rentabilidade das empresas.

De forma resumida, verifica-se que entre os indicadores de desempenho financeiro ligados ao crescimento corporativo há somente relação positiva entre as variáveis, sendo a correlação entre a proporção de vendas no exterior e o faturamento da companhia a relação mais forte entre as variáveis, podendo ser considerada forte. Por outro lado, analisando os indicadores contábeis de rentabilidade, o processo de internacionalização apresenta relação fraca negativa com dois das quatro variáveis analisadas, sendo apenas a variável retorno sobre o patrimônio líquido classificada como fraca positiva.

\section{CONSIDERAÇÕES FINAIS}

As principais teorias sobre internacionalização de empresas tendem a revelar a decisão de atuar no mercado externo como sendo um processo complexo e de risco elevado, devido à necessidade de adaptação operacional, ora por requisitos globais, ora por exigências locais de onde a empresa está inserida. Apesar disso, sabe-se que o mundo globalizado oferece diversas oportunidades às empresas que resolvem atuar no mercado externo. Apesar das ameaças relacionadas aos riscos e barreiras para se estabelecer fora do cenário doméstico, há uma tendência dessas empresas se beneficiarem substancialmente da expansão global (Czinkota, Ronzainen et al., 2004, p. 3). Bartlett, Ghoshal e Birkinshaw (2004) especificam três benefícios que merecem o devido destaque: vantagem no suprimento de matéria-prima, oportunidade de crescimento não possibilitada pelo mercado doméstico e vantagem operacional sobre os concorrentes utilizando-se dos recursos em localidades geográficas que lhes permitam algum tipo de ganho.

Buscando compreender os postulados apresentados anteriormente e os benefícios gerados pela internacionalização, analisou-se, por meio deste estudo, a relação entre o índice de internacionalização, mensuração dos processos organizacionais externos ao país sede da empresa e o desempenho financeiro das organizações. Este último, baseado no constructo do desempenho financeiro das organizações em: crescimento e rentabilidade (Venkatraman e Ramanujam, 1987)

Revista Ibero-Americana de Estratégia - RIAE, São Paulo, v. 10, n. 3, p. 04-21, set./dez. 2011. 
Constatou-se relação moderada/fraca positiva entre o esforço de conquistar novos mercados e a dimensão crescimento das empresas analisadas, corroborando a racionalidade da empresa em respeito aos argumentos de Bartlett, Ghoshal e Birkinshaw (2004). No entanto, a relação entre o índice de internacionalização e a faceta rentabilidade do desempenho financeiro da empresa apresenta correlações fracas e em duas das variáveis independentes nota-se relação negativa, indicando que a estratégia de internacionalização prejudica margens de rentabilidade das empresas. Nesse sentido, este estudo contribui empiricamente em verificar a não aderência da proposição de Bartlett et al. (2004), de que as empresas reconhecem a internacionalização como forma de prover crescimento para seus resultados, à realidade das empresas brasileiras que optaram por internacionalizar em sua estratégia.

Essas conclusões, aliadas à metodologia aqui empregada, parecem vislumbrar um promissor campo de pesquisa. Ademais, ainda é relativamente elementar a produção acadêmica acerca desta temática no Brasil. Desse modo, sugere-se que novas pesquisas: a) façam uso de outras medidas de internacionalização e desempenho financeiro; c) estudem períodos de tempo diferentes e mais extensos; d) analisar o processo de internacionalização de empresas já consolidadas no mercado global.

\section{REFERÊNCIAS}

Anderson, D. R. et al.(2011) Estatística aplicada à administração e economia. (2a ed.). São Paulo: Cengage Learning.

Barcellos, E. P.(2010) Internacionalização de empresas brasileiras: um estudo sobre a relação entre o grau de internacionalização e desempenho financeiro. Dissertação de Mestrado, Faculdade de Economia, Administração e Contabilidade, Universidade de São Paulo, São Paulo, Brasil.

Bartlett, C. A. et al.(2004) Transnational management : text, cases, and readings in cross-border management. (4th. ed.) Boston: McGraw-Hill.

Batista jr., Nogueira, P.(1998) Mitos da globalização. São Paulo: USP - Estudos Avançados 12.

Berk, J., Demarzo, P.(2007) Corporate finance. Boston: Addison-Wesley.

Boshoff, C., Mels, G. (1995) A causal model to evaluate the relationships among supervision, role stress, organizational commitment and internal service quality. European Journal of Marketing [S.I.], 29(2), 23 - 42.

Revista Ibero-Americana de Estratégia - RIAE, São Paulo, v. 10, n. 3, p. 04-21, set./dez. 2011. 
Estratégia de Internacionalização de Firmas Brasileiras e Desempenho Financeiro

Boston Consulting Group.(2003) BCG 100 New Global Challengers. Boston.

Boston Consulting Group.(2009) 100 New Global Challengers. Boston.

Buckley, P. J.; Casson, M. J. A.(1976) The future of the multinational enterprise. New York: Holmes \& Meier Publishers.

Contractor, F. J. et al.(2003) A three-stage theory of international expansion: the link between multinationality and performance in the service sector. Journal of International Business Studies [S.I.], v. 34, n. 1, p. 5-18.

Czinkota, M. R. et al.(2004) Mastering global markets: strategies for today's trade globalist. KY: Thomson Learning.

Dunning, J. H.(1980) Towards an eclectic theory of international production: some empirical tests. Journal of International Business Studies [S.I.], 11(1), 9-31.

Hult, G. T. M. et al.(2008) An assessment of the measurement of performance in international business research. Journal of International Business Studies [S.I.], 39(6), 1064-1080.

Inkpen, A. C., Beamish, P. W. An analysis of twenty-five years of research in the journal of international business studies. Journal of International Business Studies [S.I.], v. 25, n. 4, p. 703713, 1994.

Johanson, J., Wiedersheim-Paul, F. (1975)The internationalization of the firm - four swedish cases 1. Journal of Management Studies [S.I.], 12(3),305-323.

Lu, J. W.; Beamish, P. W. (2004) International diversification and firm performance. Academy of Management Journal [S.I.], 47(4), 598-609.

Marconi, M. D. A., Lakatos, E. M. (2003) Fundamentos de metodologia científica. (7 ed.). São Paulo: Atlas.

Mariotto, F. L. (2007)Estratégia internacional da empresa. São Paulo: Thomson Learning,.

Micklethwait, J., Wooldridge, A.(2003) A companhia: breve história de uma idéia revolucionária. Rio de Janeiro: Objetiva.

Porter, M. E. (1990) The competitive advantage of nations. New York: Free Press.

Rocha, A. (Ed.) (2003) As novas fronteiras: a multinacionalização das empresas brasileiras. Rio de Janeiro: Mauaded.

Ross, S. et al.(2009) Administração financeira. (2 ed.). São Paulo: Atlas.

Revista Ibero-Americana de Estratégia - RIAE, São Paulo, v. 10, n. 3, p. 04-21, set./dez. 2011. 
Ruigrok, W., Wagner, H. (2003) Internationalization and performance: an organizational learning perspective. Management International Review [S.I.], 43(1), 63-83.

Santos, C. (2007) Estatística descritiva - manual de auto-aprendizagem. Lisboa: Edições Sílabo.

Tanure, B., Duarte, R. G. (Eds.) (2006) Gestão internacional. São Paulo: Saraivaed.

Unctad. (2010) World Investment Report 2009: Transnational Corporations and Export Competitiveness. Recuperado em novembro de 2009, de: <http://www.unctad.org/en/docs/wir2002_en.pdf> 2010

Valor Econômico. Anuário multinacionais brasileiras.(2009) Recuperado em novembro de 2009, de: wwwvaloronline.com.br. 2009

Vasconcellos, E. (Ed.)(2008) Internacionalização, estratégia e estruturao que podemos aprender com o sucesso da Alpargatas, Azaleia, Fanem, Odebrecht, Voith e Volkswagem. São Paulo: Atlased.

Venkatraman, N., Ramanujam, V.(1987) Measurement of business performance in strategy research: a comparison of approaches. The Academy of Management Review [S.I.], 11(4), 801814.

Vernon, R.(1966) International investment and international trade in the product cycle. The Quarterly Journal of Economics [S.I.], 80(2), 190-207.

Williamson, O. E., Chandler, A. D. F. O.(1975) Markets and hierarchies, analysis and antitrust implications : a study in the economics of internal organization. New York: Free Press.

Revista Ibero-Americana de Estratégia - RIAE, São Paulo, v. 10, n. 3, p. 04-21, set./dez. 2011. 
Recebido: 18/08/2011

Aprovado: 25/10/2011

Revista Ibero-Americana de Estratégia - RIAE, São Paulo, v. 10, n. 3, p. 04-21, set./dez. 2011. 